\title{
Cardiovascular Impacts on COVID-19 Infected Patients
}

\author{
Somasundaram Raghavan ${ }^{1 *}$, R. Gayathri ${ }^{2}$, Sudhakar Kancharla ${ }^{3}$, Prachetha Kolli ${ }^{4}$, \\ J. Ranjitha ${ }^{2}$ and Vijayalakshmi Shankar ${ }^{2 *}$ \\ ${ }^{1}$ Department of Pharmaceutical Sciences, University of Tennessee Health Science Center, Memphis, TN, United States, \\ ${ }^{2} \mathrm{CO}_{2}$ Research and Green Technologies Centre, VIT University, Vellore, India, ${ }^{3}$ Devansh Lab Werks, Homewood, AL, \\ United States, ${ }^{4}$ Microgen Health Inc, Chantilly, VA, United States
}

\section{OPEN ACCESS}

Edited by:

Tharmarajan Ramprasath, Georgia State University,

United States

Reviewed by:

Dinesh Babu Somasundaram, University of Oklahoma Health Sciences Center, United States Bharathiraja Subramaniyan, University of Oklahoma Health

Sciences Center, United States

*Correspondence:

Somasundaram Raghavan sundar_btsomu@yahoo.com Vijayalakshmi Shankar vijimicro21@gmail.com

Specialty section: This article was submitted to

Cardiovascular Metabolism, a section of the journal Frontiers in Cardiovascular Medicine

Received: 22 February 2021 Accepted: 14 April 2021

Published: 13 May 2021

Citation:

Raghavan S, Gayathri R, Kancharla S, Kolli P, Ranjitha J and Shankar V (2021) Cardiovascular Impacts on COVID-19 Infected Patients. Front. Cardiovasc. Med. 8:670659. doi: 10.3389/fcvm.2021.670659
The SARS-CoV-2 virus has taken more than 2 million lives on a global scale. Over 10 million people were confirmed with COVID-19 infection. The well-known spot of primary infection includes the lungs and the respiratory system. Recently it has been reported that the cardiovascular system and coagulation mechanisms were the second major targets of biological system affected due to the viral replication. The replication mechanism of SARS-CoV-2 involves the angiotensin-converting enzyme 2- (ACE2) surface receptors of endothelial cells belonging to various organs which act as the binding site for the viral spike (S) protein of SARS-CoV-2. The COVID-19 virus has been recently listed as a primary risk factor for the following cardiovascular conditions such as pericarditis, myocarditis, arrhythmias, myocardial injury, cardiac arrest, heart failure and coagulation abnormalities in the patients confirmed with COVID-19 viral infection. Direct and indirect type of tissue damage were the two major categories detected with cardiovascular abnormalities. Direct myocardial cell injury and indirect damage to the myocardial cell due to inflammation were clinically reported. Few drugs were clinically administered to regulate the vital biological mechanism along with symptomatic treatment and supportive therapy.

Keywords: SARS-CoV-2, severe acute respiratory syndrome corona virus 2, COVID-19, ACE2, cardiovascular diseases, cardiovascular risk factors, cardiovascular system, cardiovascular abnormalities

\section{INTRODUCTION}

COVID-19 virus has created a global pandemic situation that had never seen by the world when compared to the other major infectious outbreaks. 2,244,713 patients were died due to COVID 19 based on the World health organization (WHO) report dated on 03.02.2021 (1). It has been clinically reported that the well-known primary target area of this virus is the lungs but several other tissues, organs, and organs system were also recorded to be severely injured by viral replication. Based on the clinical reports this virus mainly invades the respiratory system, the second major area of infection were recently recorded to be the cardiovascular system and blood coagulation mechanism. Other target areas include the gastrointestinal tract, kidney, and organs representing endothelial cell with ACE2 surface marker (2). The severity of these viral infections involves various factors including age groups, gender specificity, comorbid such as diabetes, hypertension, cardiovascular disease, suppressed immune system etc. (3). This review give emphasis on cardiovascular abnormalities caused by SARS-CoV-2 virus and its treatment possibilities. 


\section{CARDIOVASCULAR CONDITIONS MANIFESTED WITH SARS-CoV-2 INFECTION}

SARS-CoV-2 acts as a risk factor for developing the following cardiac abnormalities clinically reported until 2020 which includes Myocarditis, pericarditis, myocardial injury [MI], arrhythmias, and abnormal coagulation mechanism and these conditions were manifested asymptomatically in few cases (4). The death rate due to cardiac abnormalities was reported to be high in patients especially with myocardial injury indicated with an escalated level of troponin exhibiting a short life span.

\section{FACTORS INFLUENCING CARDIAC ABNORMALITIES}

The primary factor of risk include age, (elderly individuals), high blood pressure, diabetic clinical condition, hyperglycaemia, people diagnosed with congestive cardiac failure (CCF), cancer, coronary heart disease, Atherosclerotic heart disease act as absolute lethal factors in patients confirmed with SARS-CoV$2(4)$.

\section{SYMPTOMS}

\section{General Symptoms for COVID-19 Infection}

The symptoms for SARS-CoV-2 includes common symptoms associated with common cold and flu, intermittent diarrhea, anosmia, and ageusia $(5,6)$. The manifestation of symptoms was noticed 5 days after exposure to the viral particles (7). Dyspnoea indicates the severity of infection with clinical reports of elevated levels of plasma troponin, C-Reactive-Protein (CRP), Procalcitonin (PCT) and lymphocytopenia, IL-6, D-dimer and ferritin as a resultant product of blood mediated immune response due to hyperactivation of immune cells resulting inflammatory cytokine storm $(8,9)$.

\section{Cardiac Abnormalities Due to SARS-CoV-2 Infection}

Chest pain representing the following heart conditions including ischemia, MI detected by the elevated levels of troponin, (CK) creatine kinase, natriuretic peptide (NT-Pro-BNP) were significantly noticed with few primary coronary occlusions. Both direct and indirect mechanisms of tissue damage were documented as a major cause for cardiomyopathy in the dead patient (10-12). Mortality caused by ventricular function and acute heart failure. Cardiomyopathy, asphyxia, ischemia, high metabolic demand, impairment of left ventricle, imbalanced electrolytes, proarrhythmic effect, consumptive coagulopathy, thrombogenesis in arteries as a consequence of hyperimmune response due to viral invasion were extremely recorded. Arrhythmia and cardiac arrest rank top position in cardiovascular abnormalities due to SARS-CoV-2 infection (13). The number of patients died due to cardiac arrest as a consequence of arrhythmia, and in the individual who was severely ill with COVID-19 were widely documented $(14,15)$.

\section{VARIOUS MECHANISM INVOLVED IN TISSUE DAMAGE}

Based on the mode of cellular damages caused to various tissues and organs, by viral replication mechanism, it has been categorized into direct and indirect modes resulting in cardiac and pulmonary damages (16).

\section{Direct Mechanism}

COVID-19 virus can directly invade the cardiac and pulmonary tissues by using extreme target specificity (17). The damages caused by the viral replication to the cardiac and pulmonary region were detected with direct viral contact to the damaged cells. The SARS-CoV-2 virus makes use of the ACE2 surface receptors in order to establish the cellular contact in the cardiovascular, pulmonary system $(18,19)$. Thus, the viral entry into the host cell is facilitated by binding of S-protein (glycoprotein) with ACE2 surface receptors of endothelial cells belonging to various organs, chiefly the vascular endothelial cells and cardiomyocytes were directly invaded by SARS-CoV-2 (20).

\section{The Angiotensin-Converting Enzyme}

The angiotensin-converting enzyme (ACE) are protein units distributed on the surface of endothelial cells which act as a primary target for viral invasion into the cells belonging to the cardiovascular system, gastrointestinal tract, renal system and respiratory system and type 2 pneumocytes (4). Injured host cells belonging to the upper gastrointestinal tract (GI), heart, lungs, and kidney were detected in a dead patient infected with the SARS-CoV-2 virus $(21,22)$. This indicates that these tissues were directly injured by the viral replication mechanism (23-25).

\section{Binding Mechanism}

The viral S-protein recognizes the extracellular domain of this ACE2 type 1 integral protein-containing peptidase as a targeted binding site. The diagrammatic representation of SARS-CoV2 was depicted in Figure 1. The membranous fusing of a host cell with viral spike protein is followed by the completion of binding $(26,27)$. Transmembrane Serine Protease 2 (TMPRSS2) plays a vital role in cleaving the binding site and priming of S-protein thereby facilitating the viral entry into the host cell (28-30). Phosphoinositide 5-kinase (PIKfyve), two-pore segment channel 2 (TPCN2), and cathepsin L were recently reported to be necessary for the passage of the virus into the host cell. Translation of polyprotein from viral RNA takes place, followed by assembly with genomic ribonucleotide to form virions (31-33). The transportation and release of virions from the damaged cell were carried out by the process of exocytosis. This intracellular viral replication suppresses and reduces the catalytic sensitivity of ACE2 surface molecules at its extracellular domain $(34,35)$.

\section{Indirect Mechanism}

Systemic inflammation (SI) is the indirect mode of the viral mechanism causing damages to the cardiomyocytes. It has been reported that there is an elevated level of plasma troponin detected with a linear positive correlation with elevated CRP 


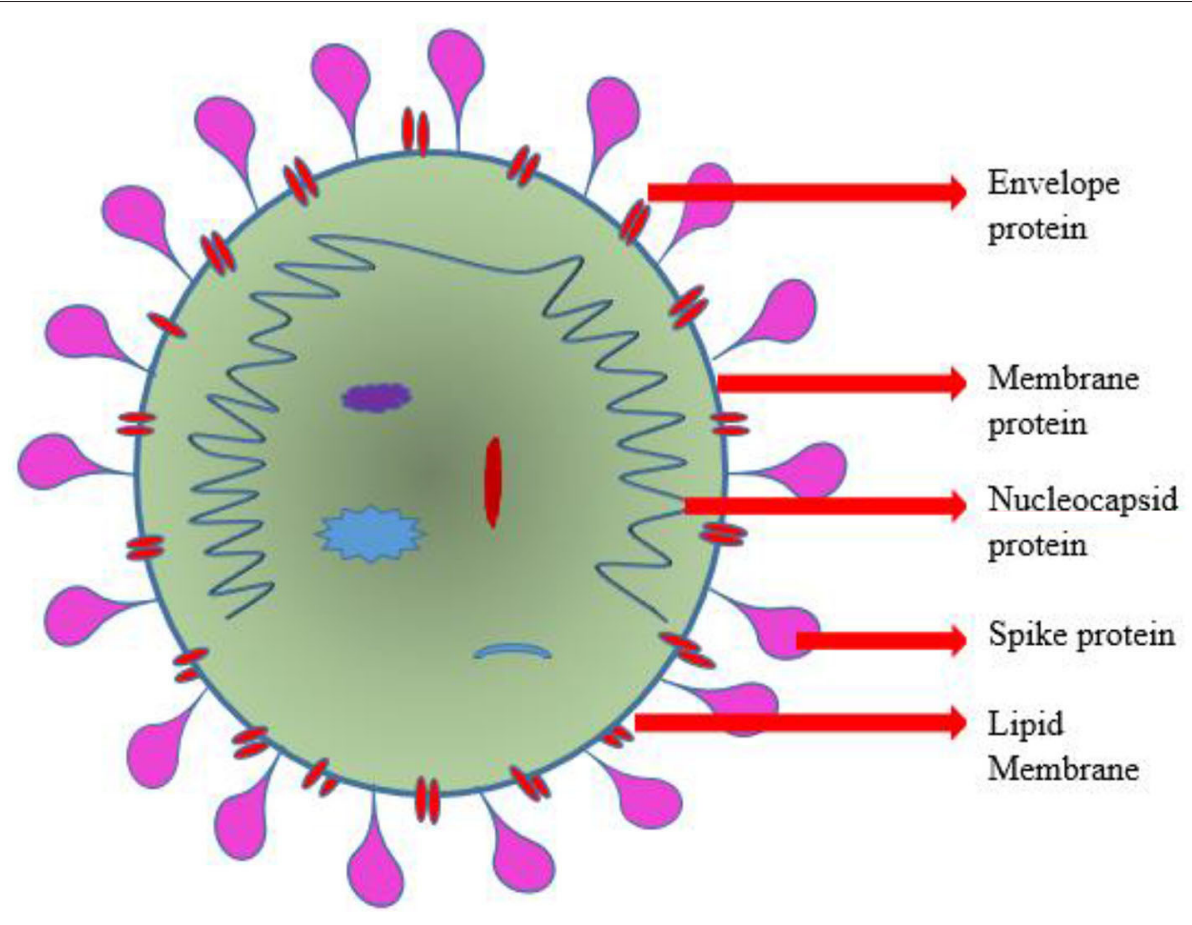

FIGURE 1 | Schematic representation of the structure of coronavirus (SARS-CoV-2).

in blood. Procalcitonin (PCT) was also expressed along with CRP. This indicates that SI is a root cause for the damage of cardiomyocytes. Cytokine storm is also a part of an indirect mechanism leading to the damages of cardiomyocytes. Huang et al. (10) emphasized the biochemical reactions involved in cytokine storm detected in SARS-CoV-2 infected patients. It has been clinically observed that the balance between TH1 and TH2 was disturbed leading to cytokine storm ultimately resulting in the damage of cardiomyocytes. Once the postinfective cytokine signaling molecule was released it reduces the vascular flow in coronary arteries, lowers the $\mathrm{O}_{2}$ supply, and destabilizes the coronary plaque and formation of microvascular thrombosis. Persistent CVD (cardiovascular disease) becomes unpredictable and unstable due to an abnormal balance of high metabolic demand induced by a viral infection and decreased cardiac reserve. Acute Myocardial infraction (AMI-type 2) due to the uprise of metabolic demand by cardiomyocytes were documented in patients confirmed with SARS-CoV2. There is an extreme chance for rupturing of coronary plaque and cardiac failure followed by SI in individuals with existing CAD (coronary artery disease). Abnormal coagulation has been recorded but the biochemical mechanism remains undiscovered. Arrhythmias were widely reported in COVID-19 infected individuals. Lymphopenia was highly associated with cytokine storm. Hypoxia, tachypnoea were few other clinical complications developed due to indirect viral mechanism. Multiple organ dysfunction Syndrome due to hyperimmune activity is a major cause of fatality (10).

\section{CARDIAC VASCULAR ABNORMALITIES BY SARS-CoV-2 INFECTIONS}

Cardiovascular impairment arises in the stage only after the occurrence of respiratory distress. Most of the clinical conditions were reported due to a fall in $\mathrm{O}_{2}$ supply leading to tissue injury and cell death in the heart (36). The abnormalities by SARS$\mathrm{CoV}-2$ infection has been clearly shown in Figure 2. Direct viral entry into the heart occurs only after the pulmonary viral invasion, indirect damage mechanism also begins with triggering of a hyperimmune reaction during viral invasion into the lungs. Among the $50.1 \%$ inpatients, nearly $40.1 \%$ were reported with cardiovascular disorders $(37,38)$.

\section{Myocardial Injury}

It has been clinically proven that SARS-CoV-2 itself causes acute MI and other cardiac disorders in patients without a history of any cardiovascular disorders $(39,40)$. Acute MI involves both direct and indirect viral mechanism resulting in the damage of cardiomyocytes (41). Among 52 patients with severe illness, 29\% of the patients in ICU showed elevated levels of cardiac troponin $29 \mathrm{ng} / \mathrm{L}$ indicating acute MI $(42,43)$. The cardiac troponin was observed to be $29 \mathrm{ng} / \mathrm{L}$ in 1 out of 95 survivors and 34 dead patients showed the same levels out of 54 dead individuals. Among $8-12 \%$ of patients showed $99 \%$ of increased cardiac troponin with exacerbated impacts $(12,44)$. The mean difference of $25.6 \mathrm{ng} / \mathrm{L}$ was observed between patients with and without cardiac abnormalities after infection with SARS-CoV-2 $(45,46)$. 


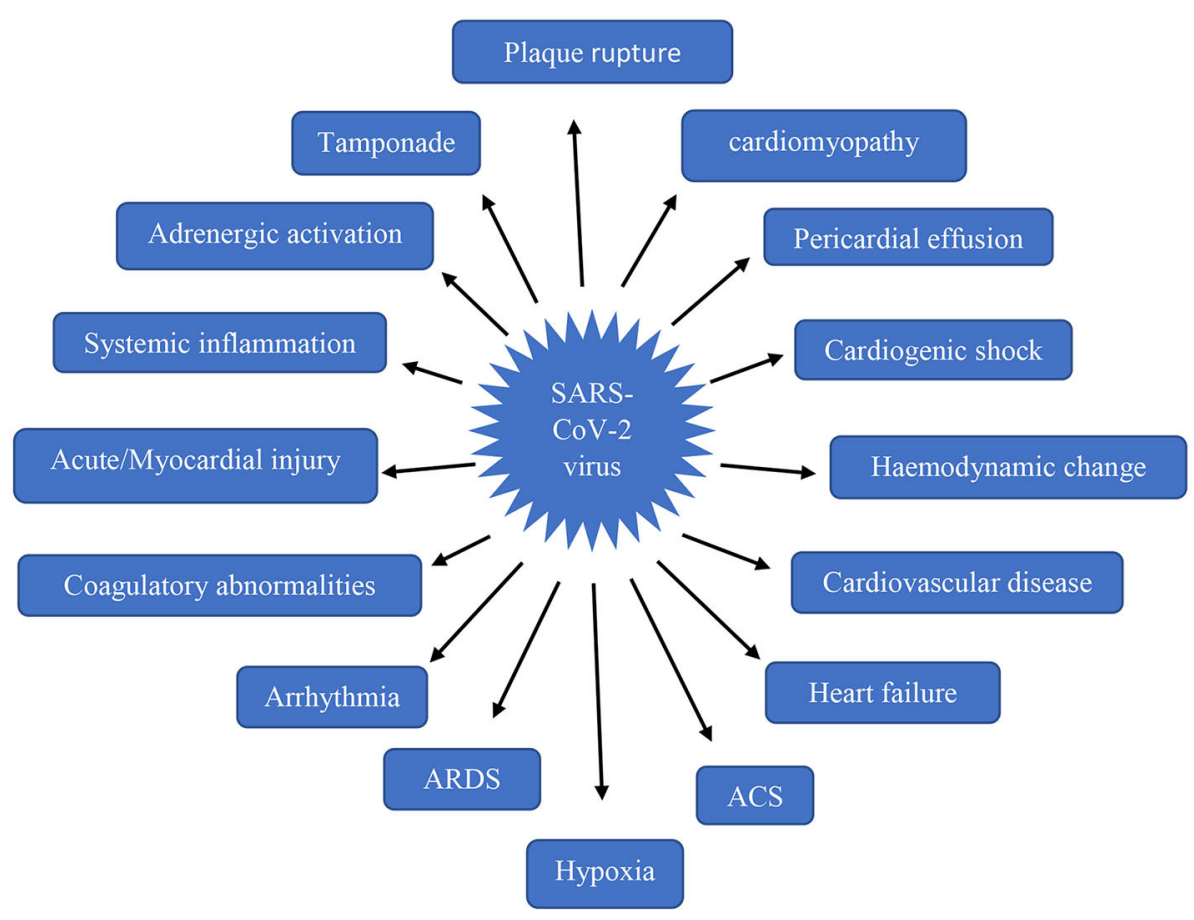

FIGURE 2 | Cardiovascular conditions associated with SARS-CoV-2 virus.

Nearly $99 \%$ of the patient with cardiac abnormalities showed an intensification of previously diagnosed cardiac conditions due to the impact of the viral mechanism $(26,47,48)$. Examination of tissues from the endocardium of an infected Italian inpatient was detected with acute MI, cardiac shock (CS), acute lymphocytic cardiomyopathy $(49,50)$. Numerous cases were diagnosed with cardiomyopathy associated with SARSCoV-2 infection only with technical diagnostic images with the absence of histopathological analysis. Increased levels of biochemical markers such as creatine kinase, interleukin-6 (IL6), transaminases, serum ferritin, lactate dehydrogenase, Ddimer along escalated prothrombin time noticed in dead patients implies that elevation of cytokine and substance mediating proinflammation reactions analogous to hypercytokinemia and systemic inflammation. Release of IL-6, Interferon gamma (IFN$\beta$ ) occurs as a consequence of hypercytokinemia and Tumor Necrosis Factor- $\alpha$ (TNF- $\alpha$ ), interleukin-1 $\beta$ (IL-1 $\beta$ ), and IL-6 (51, 52). In Acute COVID-19 disease cardiovascular syndrome the degree of severity that the COVID-19 virus as the sole cause for acute MI, LV-dysfunction, increase in cardiac troponin remains uncertain. There is an unproven theory stating that microthrombogenesis as a consequence of abnormal coagulation mechanism would be serving as the main cause for MI but still, there is clinical evidence indicating the presence of pulmonary emboli. The pathophysiology cascade for injury and death of heart cells via direct damage is yet to be discovered (53).

\section{Patterns of MI}

In general, two types of patterns were recorded in tissue injury so far with COVID-19 infected patients.

\section{Type 1}

Manifestation of symptoms on 4th day of infection. Cardiac troponin levels were recorded to be $>2.5-4.4 \mathrm{pg} / \mathrm{mL}$ and in patients who were alive and $>8.7 \mathrm{pg} / \mathrm{mL}$ in dead patient. Subsequent rise in cardiac troponin was listed in the Table $\mathbf{1 .}$

The duration between 15 and 20 days of infection was calculated to the statistically meantime for the death of the patients based on the death report of non-survived individuals. Other biomarkers levels suggested a cytokine storm as an additional mechanism and not MI as the sole cause of death.

\section{Type 2}

Infected individuals with a history of cardiovascular disorder showed the difference when compared to the pattern shown by patients with absence of CVD representing viral or stress cardiomyopathy was recorded (55). One patient showed chest pain with elevated ST-segment in the ECG report with the absence of a coronary occlusion. EKG reports indicated LVimpairment with $27 \%$ ejection fraction, along with troponin $10.1 \mathrm{ng} / \mathrm{mL}$, and NT-proBNP - >21,000 pg/mL, normalization of ejection fraction and biochemical markers were observed after 28 days when the patient is provided with steroids and Ig via IV line $(56,57)$. A Chinese man with the age of 63 without any 
CAD history was suffered from severe respiratory distress and fulminant cardiomyopathy showing LV enlargement of $6.1 \mathrm{~cm}$, suppressed LV physiology with $32 \%$ ejection fraction, escalated troponin level more than $11 \mathrm{ng} / \mathrm{mL}$ and NT-proBNP around $22,000 \mathrm{pg} / \mathrm{mL}$. ECMO along with Ig-IV, steroid, anti-viral and renal replacement therapy was administered to treat his cardiac shock based on the severity of his condition (58). Recovery of this patient was observed after 15 days with an improved ejection fraction of the left ventricle. The two patients were commonly treated with glucocorticoids but their effects remain uncertain and currently the use of glucocorticoids was terminated based on the guidelines issued by CDC and WHO. Palpitations and chest patient were reported among Chinese patients without common symptoms of SARS-CoV-2 (59).

\section{Cardiomyopathy or Myocarditis}

Based on the data obtained from the meta-analysis of 1,527 patients included in 6 studies, around $>8 \%$ of inpatients were reported with acute cardiomyopathy. According to another meta-analysis with 4 studies with a sample size of 341 for an elevated level of cardiac troponin, analysis was reported with $36 \%$ out of 341 infected individuals. Continuous monitoring of cardiac troponin level from the onset of infection until recovery or death was highlighted by the investigator with the above mentioned statistical mean value $(11,60)$.

\section{Arrhythmia}

From 138 hospitalized individuals nearly 44\% was reported with arrhythmia $(7,38)$. One of the cardiovascular abnormalities to be highly recorded was acute myocardiopathy with $5.9 \%$ ventricular arrhythmia which includes ventricular tachycardia and ventricular fibrillation $(61,62)$. Arrhythmia may occur as a result of precipitation caused by imbalanced electrolytes $(63,64)$. Tachyarrhythmias was observed due to the fluctuation of $\mathrm{Na}$ with $\mathrm{K}$ levels associated with virus interaction with the renin-angiotensin-aldosterone system $(65,66)$. Based on the CDC report from the U.S.A around $18.5 \%$ of patients administered with mechanical ventilation developed atrial arrhythmias (67-69). The FDA (Food and Drug Administration) stated that chloroquine phosphate and hydroxychloroquine sulfate act as potential agents to induce arrhythmia (7, $70)$.

\section{Abnormal Coagulatory Mechanism}

Venous thromboembolism, thrombogenesis in microvascular vessels were major clinical conditions due to abnormal coagulation mechanism clinically reported so far. The death rate of hospitalized individuals was observed to be high due to escalated D-dimer levels with $>1 \mathrm{~g} / \mathrm{L}$. Comparative study of D-dimer levels between surviving and non-surviving hospitalized individuals showed $71.4 \%$ of non-survivors exhibited abnormal intravascular coagulatory mechanism indicated by Fibrin degradation product and d-dimer $(71,72)$. Thromboembolism can be strongly suspected in patients with severe illness as an outcome of hypoxia and hemodynamically unstable condition. Infected individuals immobilized for a
TABLE 1 | Variations in the level of cardiac troponin in non-survived patients with MI (54).

\begin{tabular}{llcc}
\hline S. No & Biochemical marker & $\begin{array}{c}\text { Levels of marker } \\
\text { represented in } \mathbf{~ g g / m L}\end{array}$ & No of days \\
\hline 1. & Cardiac troponin & 24.7 & On day 7 \\
2. & Cardiac troponin & 55.7 & On day 13 \\
3. & Cardiac troponin & 134.5 & On day 19 \\
4. & Cardiac troponin & 290.6 & On day 22 \\
\hline
\end{tabular}

longer period can give rise to (Disseminated intravascular coagulation) DIC and (Venous thromboembolism) VTE (2). In general tissue plasminogen activator (tPA) and plasminogen activator inhibitor-1 (PAI-1) activates the cascade for the lysis of fibrin. In the case of SARS-CoV2 infected individuals, the following reactions will trigger the cascade for thrombogenesis which includes the mass discharge of cytokines or cytokine storm syndrome which triggers inflammatory reactions, activates the platelets, endothelial impairment, hypoxiation and disruption of haemostatics in infected individuals immobilized for a longer period (73).

\section{Other Cardiac Disorders}

Arrythmia more than $44 \%$ of in patients in intensive care units was recorded with arrythmias along with $61 \%$ showed ARDS, $30.63 \%$ with cardiogenic shock with a sample size of 138 patients. From the critically ill 191 patients heart failure was noticed around $12 \%$ in severely ill individual and $52 \%$ dead individuals. Other complications include coagulation abnormalities with elevated levels of biochemical markers along with acute pulmonary embolism. Based on the report of CDC in china over $10 \%$ of people were died due to Cardiovascular abnormalities among 72,314. Around $44 \%$ of Patients recovered from SARS-CoV-2 infection with CVD history were recorded with worse outcomes of those clinical conditions $(74,75)$.

\section{TREATMENT}

ACEi (Angiotensin-converting enzyme inhibitor) and ARBs (Angiotensin receptor blockers) are angiotensin receptors inhibitors and blockers used to inhibit the communicating between the host cell with the virus. In the earlier stage, it was uncertain but based on the recent data it was found to be useful for protecting acute pulmonary injury caused by internalization of SARS-CoV-2 with host cell-based on murine model test results (54). Anti-ACE2 molecules, TMPRSS2 inhibitor molecules and S1 protein subunits- inhibitors were experimentally proven to the potential agents for reducing viral replication inside the host cells (39). The coronary plaques were stabilized with drugs such as aspirin and statins (4). Symptomatic and supportive treatment requires administration of analgesia, antipyretic, $\mathrm{O}_{2}$ supply via a nasal cannula or Hudson mask based on the health condition of an infected person. Mechanical ventilation with 
low tidal volume is used to regulate hypoxia. Extracorporeal lung replacement procedure must be administered if invasive ventilation is insufficient (7-9). Administration of antiviral drugs such as lopinavir/ritonavir on 199 infected individuals was recorded with positive results showing significantly decreased viral load with improved symptoms. Remdesivir drug tested on cell lines also had a positive result with an inhibitory effect on the replicating mechanism of SARS-CoV-2 (76). The use of the above-mentioned antiviral drugs like hydroxychloroquine was discontinued for a short trial period due to the risk of developing hyperimmune reactions producing the clinical conditions - arrhythmia leading to death $(77,78)$. Individuals recovered from SARS-CoV-2 infection with MI were recommended not to undergo activities like exercise, sports and aerobics for 6-7 months to reach normal troponin levels confirmed with biochemical test with NMR diagnosis. Venoarterial extracorporeal membrane oxygenation (VAECMO) and extracorporeal membrane oxygenation (ECMO) were found to be useful for rescuing patients with refractory shock or ventricular arrhythmias as a result of acute COVID19-cardiovascular syndrome. It has been clinically recorded that a patient was successfully saved with the use of VA-ECMO $(46,79)$.

\section{REFERENCES}

1. Coronavirus WHO. Disease (COVID-19) [Internet]. Available online at: https://covid19.who.int/ (accessed February 10, 2021).

2. Zadow EK, Wundersitz DWT, Hughes DL, Adams MJ, Kingsley MIC, Blacklock HA, et al. Coronavirus (COVID-19), coagulation, and exercise: interactions that may influence health outcomes. Semin Thromb Hemost. (2020) 46:807-14. doi: 10.1055/s-0040-1715094

3. Golemi MI, Golemi L, Tafur, Pursnani AA. The novel coronavirus disease (COVID-19) and its impact on cardiovascular disease. Card Rev. (2020) 28:163-76. doi: 10.1097/CRD0000000000000317

4. Kwenandar F, Japar KV, Damay V, Hariyanto TI, Tanaka M, Lugito NPH, et al. Coronavirus disease 2019 and cardiovascular system: a narrative review. IJC Heart Vascul. (2020) 29:100557. doi: 10.1016/j.ijcha.20201 00557

5. Radke RM, Frenzel T, Baumgartner H, Diller HGP. Adult congenital heart disease and the COVID-19 pandemic. Heart. (2020) 106: 13029. doi: 10.1136/heartjnl-2020-317258

6. Wu Z, McGoogan JM. Characteristics of important lessons from the coronavirus disease 2019 (COVID-19) outbreak in China: summary of a report of 72314 cases from the Chinese Centre for Disease Control Prevention. JAMA. (2020) 323:1239-42. doi: 10.1001/jama.202 02648

7. Zhou F, Yu T, Du R, Fan G, Liu Y, Liu Z, et al. Clinical course and risk factors for mortality of adult inpatients with COVID-19 in Wuhan, China: a retrospective cohort study. Lancet. (2020) 395:105462. doi: 10.1016/S0140-6736(20)30566-3

8. Young BE, Ong SWX, Kalimuddin S. Epidemiologic features clinical course of patients infected with SARS-CoV-2 in Singapore. JAMA. (2020) 323:148894. doi: 10.1001/jama.20203204

9. Phua J, Weng L, Ling L, Egi M, Lim CM, Divatia JV, et al. Intensive care management of coronavirus disease 2019 (COVID19): challenges and recommendations. Lancet Respir Med. (2020) 8:506-17. doi: 10.1016/S2213-2600(20)30161-2

10. Huang C, Wang Y, Li X. Clinical features of patients infected with 2019 novel coronavirus in Wuhan, China. Lancet. (2020) 395:497506. doi: 10.1016/S0140-6736(20)30183-5

\section{CONCLUSION}

Recent reports of cardiovascular complications due to COVID19 was clinically reported on a wide scale. Infection to SARS-CoV-2 has become a risk factor for cardiac disorders lately. Compared to adults, aged persons were prone to more complications and severity of cardiac conditions due to COVID-19 infection. Symptomatic and Supportive treatment was clinically administered for COVID-19 infected patients. Phase I and II clinical trials are currently in progress in many countries. The vaccine under clinical trials exhibits only short immunogenic effects which lead to administration of booster dose after $72-150$ days to increase its efficacy up to $90 \%$. To avoid infection preventive measures including usage of face mask, sanitiser, social distancing has to be followed until the discovery of a vaccine with prolonged immunogenic effects.

\section{AUTHOR CONTRIBUTIONS}

SR: conceptualization and investigation. RG: resources and validation. SK, PK, and JR: formal analysis. VS: conceptualization and supervision. All authors contributed to the article and approved the submitted version.

11. Guo T, Fan Y, Chen M. Cardiovascular implications of fatal outcomes of patients with coronavirus disease 2019 (COVID-19). JAMA Cardiol. (2019) 5:1-8. doi: 10.1001/jamacardio.20201017

12. Zeng JH, Liu XY, Yuan J, Wang F, Wu W, Li J, et al. First case of COVID-19 complicated with fulminant myocarditis: a case report and insights. Infection. (2020) 48:773-7. doi: 10.1007/s15010-020-01424-5

13. Kwong JC, Schwartz KL, Campitelli MA, Chung H, Crowcroft NS, Karnauchow T, et al. Acute myocardial infarction after laboratory-confirmed influenza infection. N Engl J Med. (2018) 378:345-53. doi: 10.1056/NEJMoa1702090

14. Mekontso DA, Boissier F, Charron C. Acute or pulmonale during protective ventilation for acute respiratory distress syndrome: prevalence, predictors, clinical impact. Int Care Med. (2016) 42:862-70. doi: 10.1007/s00134-015-4141-2

15. Li Y, Li H, Zhu S. Prognostic value of right ventricular longitudinal strain in patients with COVID-19. JACC Cardiovasc Imag. (2020) 13:228799. doi: 10.1016/j.jcmg.2020.04014

16. Lazaridis C, Vlachogiannis NI, Bakogiannis C, Spyridopoulos I, Stamatelopoulos K, Kanakakis I, et al. Involvement of cardiovascular system as the critical point in coronavirus disease 2019 (COVID-19) prognosis and recovery. Hellenic J Cardiol. (2020) 61:381-95. doi: 10.1016/j.hjc.2020.05004

17. Shi S, Qin M, Shen B, Cai Y, Liu T, Yang F, et al. Association of cardiac injury with mortality in hospitalized patients with COVID-19 in Wuhan, China. JAMA Cardiol. (2020) 5:802-10. doi: 10.1001/jamacardio.20200950

18. Yang, Jin CZ. An acute respiratory infection runs into the most common noncommunicable epidemic-COVID-19 and cardiovascular diseases. JAMA Cardiol. (2020) 5:743-4. doi: 10.1001/jamacardio.20200934

19. Hoffmann M, Kleine-Weber H, Schroeder S, Krüger N, Herrler T, Erichsen S, et al. SARS-CoV-2 cell entry depends on ACE2 and TMPRSS2 and is blocked by a clinically proven protease inhibitor. Cell. (2020) 181:27180. doi: 10.1016/j.cell.2020.02052

20. Wan Y, Shang J, Graham R, Baric RS, Li F. Receptor recognition by the Novel Coronavirus from Wuhan: an analysis based on decade-long structural studies of SARS Coronavirus. J Virol. (2020) 94:1-9. doi: 10.1128/JVI00127-20

21. Bavishi C, Maddox TM, Messerli FH. Coronavirus disease 2019 (COVID19) infection and renin angiotensin system blockers. JAMA Cardiol. (2020) 5:745-7. doi: 10.1001/jamacardio.20201282 
22. Klimas J, Olvedy M, Ochodnicka MK. Perinatally administered losartan augments renal ACE2 expression but not cardiac or renal Mas receptor in spontaneously hypertensive rats. J Cell Mol Med. (2015) 19:196574. doi: $10.1111 / \mathrm{jcmm} 12573$

23. Ferrario CM, Jessup J, Chappell MC. Effect of angiotensinconverting enzyme inhibition and angiotensin II receptor blockers on cardiac angiotensin-converting enzyme 2. Circulation. (2005) 111:2605-10. doi: 10.1161/CIRCULATIONAHA.104510461

24. Soro-Paavonen A, Gordin D, Forsblom C. FinnDiane Study Group. Circulating ACE2 activity is increased in patients with type 1 diabetes and vascular complications. J Hypertens. (2012). 30:375-83. doi: 10.1097/HJH0b013e32834f04b6

25. Donoghue M, Hsieh F, Baronas E. A novel angiotensin-converting enzymerelated carboxypeptidase (ACE2) converts angiotensin I to angiotensin 1-9. Circ Res. (2000) 87:e1. doi: 10.1161/01.RES.87.5e1

26. Li W, Moore MJ, Vasilieva N, Sui J, Wong SK, Berne MA, et al. Angiotensinconverting enzyme 2 is a functional receptor for the SARS coronavirus. Nature. (2003) 426:450-4. doi: 10.1038/nature02145

27. Kuba K, Imai Y, Rao S. A crucial role of angiotensin converting enzyme 2 (ACE2) in SARS coronavirus-induced lung injury. Nat Med. (2005) 11:8759. doi: $10.1038 / \mathrm{nm} 1267$

28. Shang J, Ye G, Shi K. Structural basis of receptor recognition by SARS-CoV-2. Nature. (2020) 581:221-4. doi: 10.1038/s41586-020-2179-y

29. Gallagher TM, Buchmeier MJ. Coronavirus spike proteins in viral entry and pathogenesis. Virology. (2001) 279:371-4. doi: 10.1006/viro.20000757

30. Wrapp D, Wang N, Corbett KS. Cryo-EM structure of the 2019nCoV spike in the prefusion conformation. Science. (2020) 367:12603. doi: $10.1126 /$ scienceabb2507

31. Hoffmann M, Kleine-Weber H, Krüger N, Müller M, Drosten C, Pöhlmann S. The novel coronavirus 2019 (2019-NCoV) uses the sars-coronavirus receptor ace 2 and the cellular protease TMPRSS2 for entry into target cells. Mol Biol. (2020) 181:271-80. doi: 10.1101/2020.01.31929042

32. Matsuyama S, Nao N, Shirato K. Enhanced isolation of SARS-CoV2 by TMPRSS2-expressing cells. Proc Natl Acad Sci. (2020) 117:70017003. doi: 10.1073/pnas2002589117

33. Ou X, Liu Y, Lei X. Characterization of spike glycoprotein of SARS-CoV-2 on virus entry and its immune cross-reactivity with SARS-CoV. Nat Commun. (2020) 11:1620. doi: 10.1038/s41467-020-15562-9

34. Shereen MA, Khan S, Kazmi A, Bashir N, Siddique R. COVID-19 infection: origin, transmission, and characteristics of human coronaviruses. J Adv Res. (2020) 24:91-8. doi: 10.1016/j.jare.2020.03005

35. Verdecchia P, Cavallini C, Spanevello A, Angeli F. The pivotal link between ACE2 deficiency and SARS-CoV-2 infection. Eur J Intern Med. (2020) 76:1420. doi: 10.1016/j.ejim.2020.04037

36. Manolis AS, Manolis TA. Cardiovascular complications of the coronavirus (COVID-19) infection: COVID-19 and the heart. Rhythmos. (2020) 15:23-8.

37. Wang D, Hu B, Hu C. Clinical Characteristics of 138 Hospitalized Patients With 2019 Novel Corona virus Infected Pneumonia in Wuhan, China. Jama. (2020) 323:1061-9. doi: 10.1001/jama.20201585

38. Yang $\mathrm{X}, \mathrm{Yu} \mathrm{Y}, \mathrm{Xu} \mathrm{J}$. Clinical course and outcomes of critically ill patients with SARS-CoV-2 pneumonia in Wuhan, China: a singlecentered, retrospective, observational study. Lan Respir Med. (2020) 8:47581. doi: 10.1016/S2213-2600(20)30079-5

39. Hendren NS, Drazner MH, Bozkurt B, Cooper LT, Jr. Description and proposed management of the acute COVID19 cardiovascular syndrome. Circulation. (2020) 141:190314. doi: 10.1161/CIRCULATIONAHA.120047349

40. Sala S, Peretto G, Gramegna M, Palmisano A, Villatore A, Vignale D, et al. Acute myocarditis presenting as a reverse tako-tsubo syndrome in a patient with SARS-CoV-2 respiratory infection. Eur Heart J. (2020) 41:18612. doi: 10.1093/eurheartj/ehaa286

41. Inciardi RM, Lupi L, Zaccone G, Italia L, Raffo M, Tomasoni D, et al. Cardiac involvement in a patient with coronavirus disease 2019 (COVID-19). JAMA Cardiol. (2020) 5:819-24. doi: 10.1001/jamacardio.20201096

42. Tavazzi G, Pellegrini C, Maurelli M, Belliato M, Sciutti F, Bottazzi A, et al. Myocardial localization of coronavirus in COVID-19 cardiogenic shock. Eur J Heart Fail. (2020) 22:911-5. doi: 10.1002/ejhf1828
43. Wood S. COVID-19 and the heart: insights from the front lines. tctMD (March 12, 2020).

44. Hu H, Ma F, Wei X, Fang Y. Coronavirus fulminant myocarditis saved with glucocorticoid and human immunoglobulin. Eur Heart J. (2021) 42:206. doi: 10.1093/eurheartj/ehaa190

45. Ruan Q, Yang K, Wang W, Jiang L, Song J. Clinical predictors of mortality due to COVID-19 based on an analysis of data of 150 patients from Wuhan, China. Int Care Med. (2020) 46:846-8. doi: 10.1007/s00134-020-05991-x

46. Maude SL, Barrett D, Teachey DT, Grupp SA. Managing cytokine release syndrome associated with novel T cell-engaging therapies. Cancer J. (2014) 20:119-22. doi: 10.1097/PPO0000000000000035

47. Zhao J, Zhou G, Sun Y. SARS coronavirus could cause multi-organ infection. Med J Chinese People's Liberation Army. (1982). Available online at: http://en. cnki.com.cn/Article_en/CJFDTotal-JFJY200308014.htm (accessed February 10, 2021).

48. Zhou G, Zhao J, Wang S. Pathological study of impact of SARS coronavirus on heart and its conduction system in SARS patients. Med J Chinese People's Liberation Army. (1982). Available online at: http://wprim.whocc.org.cn/ admin/article/ articleDetail?WPRIMID $=554623$ \&articleId $=5546231982$ (accessed February 10, 2021).

49. Oudit GY, Kassiri Z, Jiang C, Liu PP, Poutanen SM, Penninger JM, et al. SARS-coronavirus modulation of myocardial ACE2 expression and inflammation in patients with SARS. Eur J Clin Invest. (2009) 39:61825. doi: 10.1111/j.1365-2362.2009.02153x

50. Cooper LT. Myocarditis. N Engl J Med. (2009) 360:152638. doi: 10.1056/NEJMra0800028

51. Yao XH, Li TY, He ZC, Ping YF, Liu HW, Yu SC, et al. A pathological report of three COVID-19 cases by minimally invasive autopsies. Zhonghua Bing Li Xue Za Zhi. (2020) 49:411-7. doi: 10.3760/cma.j.cn112151-20200312-00193

52. Tang N, Li D, Wang X, Sun Z. Abnormal coagulation parameters are associated with poor prognosis in patients with novel coronavirus pneumonia. J Thromb Haemost. (2020) 18:844-7. doi: 10.1111/jth14768

53. Danzi GB, Loffi M, Galeazzi G, Gherbesi E. Acute pulmonary embolism and COVID-19 pneumonia: a random association. Eur Heart J. (2020) 41:1858. doi: 10.1093/eurheartj/ehaa254

54. Clerkin KJ, Fried JA, Raikhelkar J, Sayer G, Griffin JM, Masoumi A. Coronavirus (COVID-19) and cardiovascular disease. Circulation. (2019) 141:1648-55. doi: 10.1161/CIRCULATIONAHA.120046941

55. Zeng JH, Liu YX, Yuan J, Wang FX, Wu WB, Li JX, et al. First case of COVID-19 infection with Fulminant Myocarditis Complication: Case Report and Insights, Infection. (2020) 48:773-7. doi: 10.20944/preprints202003.0 180v1

56. Centers for Disease Control and Prevention. Interim Clinical Guidance for Management of Patients with Confirmed Coronavirus Disease (COVID-19). (2020). Available online at: https://www.cdc.gov/coronavirus/2019-ncov/hcp/ clinical-guidance-management-patients.html (accessed February 10, 2021).

57. World Health Organization. Clinical management of severe acute respiratory infection (SARI) when COVID-19 disease is suspected. (2020). Available online at: https://www.who.int/publications-detail/clinical-management-of-severeacute-respiratoryinfection-when-novel-coronavirus-(ncov)-infection-issuspected. doi: 10.15557/PiMR.20200003 (accessed February 10, 2021).

58. Tikellis C. Thomas MC. Angiotensin-converting enzyme 2 (ACE2) is a key modulator of the renin angiotensin system in health and disease. Int J Pept. (2012) 2012:256294. doi: 10.1155/2012/256294

59. Zou L, Ruan F, Huang M, Liang L, Huang H, Hong Z, et al. SARS-CoV-2 viral load in upper respiratory specimens of infected patients. New Eng J Med. (2020) 382:1177-9. doi: 10.1056/NEJMc2001737

60. Chen $\mathrm{T}, \mathrm{Wu} \mathrm{D}$, Chen $\mathrm{H}$. Clinical characteristics of 113 deceased patients with coronavirus disease 2019: retrospective study. BMJ. (2020) 368:m1091. doi: 10.1136/bmjm1091

61. Guan W, Ni Z, Hu Y. Clinical characteristics of coronavirus disease 2019 in China. N Engl J Med. (2020) 382:1708-20. doi: 10.1056/NEJMoa 2002032

62. Huang R, Zhu L, Xue L, Liu L, Yan X, Wang J, et al. Clinical findings of patients with coronavirus disease 2019 in Jiangsu Province, China: a retrospective, multi-center study. PLoS Negl Trop Dis. (2020) 14:e0008280. doi: 10.2139/ssrn3548785 
63. Han H, Xie L, Liu R. Analysis of heart injury laboratory parameters in 273 COVID-19 patients in one hospital in Wuhan. China J Med Virol. (2020) 92:819-23. doi: 10.1002/jmv25809

64. Chen D, Li X, Song Q, Hu C, Su F, Dai J. Hypokalemia and clinical implications in patients with coronavirus disease 2019 (COVID-19). MedRxiv [Preprint]. (2020). doi: 10.1101/2020.02.27200 28530

65. Cavusoglu Y, Kaya H, Eraslan S, Yilmaz MB. Hyponatremia is associated with occurrence of atrial fibrillation in outpatients with heart failure and reduced ejection fraction. Hellenic J Cardiol. (2019) 60:117-21. doi: 10.1016/j.hjc.2018.03006

66. Severino A, Narducci ML, Pedicino D. Reversible atrial gap junction remodeling during hypoxia/reoxygenation and ischemia: a possible arrhythmogenic substrate for atrial fibrillation. Gen Physiol Biophys. (2012) 31:439-48. doi: 10.4149/gpb_2012_047

67. Goyal P, Choi JJ, Pinheiro LC, Schenck EJ, Chen R, Jabri A, et al. Clinical characteristics of Covid-19 in New York City. N Engl J Med. (2020) 382:23724. doi: 10.1056/NEJMc2010419

68. Gautret P, Lagier J-C, Parola P. Hydroxychloroquine and azithromycin as a treatment of COVID-19: results of an open-label non-randomized clinical trial. Int $J$ Antimicrob Agents. (2020) 56:105949. doi: 10.1016/j.ijantimicag.202010 5949

69. Food US Drug Administration. Request for Emergency Use Authorization For Use of Chloroquine Phosphate or Hydroxychloroquine Sulfate Supplied From the Strategic National Stockpile for Treatment of 2019 Coronavirus Disease. Available online at: https://www.fda.gov/media/136534/download; 2020 (accessed February 10, 2021).

70. Giudicessi JR, Noseworthy PA, Friedman PA, Ackerman MJ. Urgent guidance for navigating and circumventing the QTc-prolonging and torsadogenic 33 potential of possible pharmacotherapies for coronavirus disease 19 (COVID19). Mayo Clin Proc. (2020) 95:1213-21. doi: 10.1016/j.mayocp.2020.03024

71. Zompatori M, Ciccarese F, Fasano L. Overview of current lung imaging in acute respiratory distress syndrome. Eur Respir Rev. (2014) 23:51930. doi: 10.1183/0905918000001314

72. Fan BE, Chong VCL, Chan SSW, Lim GH, Lim KGE, Tan GB, et al. Hematologic parameters in patients with COVID-19 infection. Am J Hematol. (2020) 95:E131-4. doi: 10.1002/ajh25774
73. Badawi A, Ryoo SG. Prevalence of comorbidities in the Middle East respiratory syndrome coronavirus (MERS-CoV): a systematic review and meta-analysis. Int J Infect Dis. (2016) 49:129-33. doi: 10.1016/j.ijid.2016.06015

74. Van Doremalen N, Bushmaker T, Morris DH, Holbrook MG, Gamble A, Williamson BN, et al. Aerosol and surface stability of SARS-CoV2 as compared with SARS-CoV-1. N Eng J Med. (2020) 382:15647. doi: $10.1056 / \mathrm{NEJMc} 2004973$

75. Cao B, Wang Y, Wen D, Liu W, Wang J, Fan G, et al. A trial of lopinavirritonavir in adults hospitalized with severe COVID-19. N Engl J Med. (2020) 382:1787-99. doi: 10.1056/NEJMoa2001282

76. Sheahan TP, Sims AC, Graham RL, Menachery VD, Gralinski LE, Case JB, et al. Broad-spectrum antiviral GS5734 inhibits both epidemic and zoonotic coronaviruses. Sci Transl Med. (2017) 9:3653. doi: $10.1126 /$ scitranslmedaal 3653

77. Wang M, Cao R, Zhang L, Yang X, Liu J, Xu M, et al. Remdesivir and chloroquine effectively inhibit the recently emerged novel coronavirus (2019nCoV) in vitro. Cell Res. (2020) 30:269-71. doi: 10.1038/s41422-020-0282-0

78. Mazzulli T, Farcas GA, Poutanen SM, Willey BM, Low DE, Butany J, et al. Severe acute respiratory syndrome-associated coronavirus in lung tissue. Emerg Infect Dis. (2004) 10:20-4. doi: 10.3201/eid1001030404

79. Ascierto PA, Fox B, Urba W, Anderson AC, Atkins M, Borden EC, et al. Insights from immuno-oncology: the Society for Immunotherapy of Cancer statement on access to IL-6-targeting therapies for COVID-19. J Immunother Cancer. (2020) 8:000878. doi: 10.1136/jitc-2020-000878corr1Amendment

Conflict of Interest: SK was employed by the company Devansh Lab Werks, Inc and PK was employed by the company Microgen Health Inc.

The remaining authors declare that the research was conducted in the absence of any commercial or financial relationships that could be construed as a potential conflict of interest.

Copyright $\odot 2021$ Raghavan, Gayathri, Kancharla, Kolli, Ranjitha and Shankar. This is an open-access article distributed under the terms of the Creative Commons Attribution License (CC BY). The use, distribution or reproduction in other forums is permitted, provided the original author(s) and the copyright owner(s) are credited and that the original publication in this journal is cited, in accordance with accepted academic practice. No use, distribution or reproduction is permitted which does not comply with these terms. 